Fortunately the principles of flexibility and experiment are being applied in practice. One speaker at the conference described a one-man rural centre, and another plans for one for 16 doctors. At one relatively remote centre there are good diagnostic facilities and consultant sessions, and at another neither of these is provided, since the district hospital is round the corner. At one centre some patients are initially seen by a nurse, and at another the doctors make it a rule to speak personally to every patient who telephones. At yet another centre a pilot scheme for reducing visiting by bringing the patients to the centre is to be tried. It is clear, however, that even more flexibility is needed. Many speakers complained of sudden large increases in their bills for maintenance and ancillary help, often without notice, and the boundary between local-authority and general-practitioner services in some centres is still too rigid.

Health centres are not the only means of providing facilities for good medical practice. There are a few privately built group-practice centres which look and work as well as any health centre. Nor do health centres necessarily have to be paid for out of public funds-that at Witney, near Oxford, was built with private money. Nevertheless, in future most of them are likely to be financed by the State in one way or another. For this reason alone it is important that experiments should continue. More medical students should be able to see medical practice at health centres. In particular at least one centre should be built adjacent to a district general hospital. Family doctors working there should have access to the hospital diagnostic services and to beds. And they would meet their consultant colleagues on equal terms.

\section{Intra-arterial Chemotherapy for Recurrent Neoplasms}

Systemic administration of cytotoxic agents is the most valuable form of treatment for the leukaemias and widespread lymphomas, and useful remissions are regularly achieved. In chorion-carcinoma many reports of cure are now on record. For most solid tumours, however, systemic chemotherapy is of limited value because the local action is overshadowed by its toxic effects, especially on the bone marrow and gastrointestinal epithelium.

C. T. Klopp and his colleagues' in 1950 pioneered the use of intra-arterial injection to localize the effects of cytotoxic agents in patients with cancer confined to one region. Almost a decade later O. Creech ${ }^{2}$ and R. D. Sullivan ${ }^{3}$ and their colleagues elaborated the original simple injection technique along lines predicted by Klopp. They achieved intensification of the local effect combined with limitation of the general toxicity by two methods: either the affected region was perfused through an extracorporeal circulation, or when simple intra-arterial infusion of the drug was used an antagonist was given in the systemic circulation to block toxic effects on normal tissues.

All these workers reported much better regression of disease than that obtained with cytotoxic agents given by the conventional systemic route. Understandably, widespread interest and enthusiasm were engendered and a spate of published work followed. The early impetus is now subsiaing and it is becoming possible to view the merits of intra-arterial chemotherapy in truer perspective.

Regional extracorporeal perfusion using a pump-oxygenator has achieved an established place in the management of uncontrolled malignant melanoma confined to a limb. ${ }^{4 s}$ Worthwhile palliation and sometimes prolonged freedom from signs of local disease can be obtained, so that major amputation is seldom required; the complication rate is acceptably low.

Simple intra-arterial injection or infusion with or without a systemic antidote has been used most often in the treatment of cancer in the head and neck, though it is also of some value in the treatment of pelvic ${ }^{6}$ and hepatic ${ }^{7}$ tumours. In 1962 G. Westbury and his colleagues ${ }^{8}$ reported the results of treatment with intra-arterial methotrexate and intramuscular citrovorum factor in 26 patients with cancer of the head and neck which had recurred after surgery or radiotherapy or both. They noted only one worthwhile response and stressed the considerable morbidity and mortality associated with the method, and suggested that the sclerosing effect of previous irradiation on the vascular bed had impeded access of the agent to the tumour cells. H. J. Espiner and his co-workers, ${ }^{9}$ reporting their own experience, observed the best results in patients in whom chemotherapy was the primary form of treatment ; the worst results were in those receiving chemotherapy soon after radiotherapy had failed. Others have since drawn similar conclusions. ${ }^{10}$ More recently $S$. Tinde ${ }^{11}$ has described a trial of intra-arterial infusion in patients with recurrence of neoplasms after surgery or radiotherapy or both. More than half had tumours of the head and neck; the remainder suffered from lesions of the bowel, bladder, cervix, or liver. He concluded that real benefit was uncommon and that the substantial morbidity and mortality limited the use of the method as a means of palliation. D. F. N. Harrison ${ }^{12}$ has attempted to reduce the dangers of intra-arterial therapy in certain types of cancer of the head and neck by giving short-term infusions under whole-body hypothermia. He makes the salutary comment that the treatment should not be worse than the disease.

For the time being the primary management of choice in localized cancer is surgery or radiotherapy or a combination of both. Intra-arterial chemotherapy may prove to be a worthwhile adjunct in certain instances where the orthodox weapons offer small hope of control. If so it should usually constitute the initial attack, since the operation and ionizing radiation each in its own way damages the vascular bed of the tumour. Any possible advantage in terms of control of the disease must be weighed against the very real dangers associated with the method. The indications for this treatment are broader in those parts of the world where radiotherapy is not available.

In the control or palliation of localized malignant disease recurring after operation or irradiation intra-arterial therapy has proved to be largely disappointing, disturbingly hazardous,

Klopp, C. T., Alford, T. C., Bateman, J., Berry, G. N., and Winship. T., Ann. Surg., 1950, 132, 811.

${ }^{2}$ Creech, O., jun., Krementz, E. T., Ryan, R. F., and Winblad, J. N.

ibid., 1958, 148, 616.
Sullivan, R. D., Miller, E., and Sykes, M. P., Cancer (Philad.), 1959. 12,1248 .

Creech, O., jun., and Krementz, E. T., f. Amer. med. Ass., 1964, 188,

855.
Siehlin, J. S., jun., and Clark, R. L., Amer. F. Surg., 1965, 110, 366

Moore, M. R. R., and Newton, K. A., Cancer Chemother. Rep., 1964 41, 19.

Sullivan, R. D., and Zurek, W. Z., F. Amer. med. Ass., 1965, 194, 481 .

Westbury, G., Newton, K. A., Humble, J. G., Ford, H. T., Pegg,

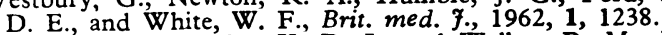

Espiner, H J., Vowles, K. D J., and Walker, R. M., Lancet, 1962. 1, 177 .

Helman, P., Sealy, R., Malherbe, E., and Anderson, J., ibid., 1965,

1, 128. Tindel, S., F. Amer. med. Ass., 1967, 200, 913.

': Harrison, D. F. N., f. Laryng., 1967, 81, 173. 
and burdensome to patient and doctor. If indicated at all, it should certainly be conducted by an experienced team and not by the occasional practitioner.

\section{Clinical Lessons from Develop- mental Neurology}

The Mental Health Research Fund lecture for 1967 was given by a developmental neurologist, Professor H. F. R. Prechtl (p. 763 of this week's B.M.f.), on the sequelae of prenatal and perinatal complications. Some people might think the choice of speaker and subject rather remote from the field of mental health. This is not the case, however, for it reflects an increasing awareness of the fact that neurological, behavioural, educational, and psychiatric problems in childhood and later years may all have their origins and first manifestations in the early months of life. The statistical data and carefully reasoned discussion of Prechtl's presentation contain important lessons about the mechanisms of neurological disturbances and the techniques of neurological examination in infancy.

Many consider that a newborn baby is either completely normal or patently the reverse. Linked with this view is the notion that if a baby does not come to notice as a result of the presence of obvious symptoms and signs then all is well and further examination is unnecessary. This may be true of the immediate future, but it is the more distant outlook that counts. The aim is that the child should have every chance of growing into a mentally and physically healthy adult. $H$. Knobloch and her colleagues ${ }^{1}$ have challenged the correctness of the " all or none" concept. These workers suggested that there was a "continuum of neurological damage," ranging from gross defects to initial minor damage with later sequelae, and this hypothesis is strengthened by Prechtl's findings. If their view is correct then detailed neurological examination of neonates is necessary to detect those with less obvious lesions who may later develop other more serious defects. To do this we need to be sure that our diagnostic tools are sufficiently precise for the task.

Prechtl's observations show that our present clinical techniques are unsatisfactory. Comparing the results of his methods of examination with those obtained by classical neurological techniques, he found that, though all the babies considered abnormal by the classical methods also scored poorly in his examination, many babies who appeared to be normal on the classical type of examination had low scores in his examination and also developed later sequelae. Prechtl's technique ${ }^{2}$ consists of a battery of quantitative observations made under strictly controlled conditions. This is time-consuming work which is not easily adapted to clinical practice. Nevertheless, it should be studied so that the routine neurological methods used in diagnosis may be improved.

Important applications arise from this work concerning the rearing of young babies. Some of the difficulties which commonly occur in the rearing of young babies are attributed to the inexperience or fault of the mother. Possibly there is a

\footnotetext{
' Knobloch, H., Rider, R., Harper, P., and Pasamanick, B., f. Amer. med. Ass., 1956, 161, 581 .

'Prechti, H. F. R., and Beintema, D., The Neurological Examination of the Full-term Newborn Infant. Little Club Clinics in Developmental Medicine, 1964, No. 12, London.

- Sheridan, M. D., Mon. Bull. Min. Hlth Lab. Serv., 1962, 21, 238.

- Richards, I. D. G., and Roberts, C. J., Lancet, 1967, 2, 711.
}

neurological basis for them which a Prechtl type of examination might reveal. Moreover, these minor neurological disturbances may be sufficient to affect the early behaviour of the infant and impair the mother-child interaction. This important period of emotional development is already being studied extensively, and everyone concerned should take note of Prechtl's work.

The concept of the " at risk" infant, which was introduced by Sheridan ${ }^{3}$ to stimulate the early detection of handicaps, has been criticized because of the unsatisfactory criteria of risk." Those concerned with finding satisfactory criteria might consider Prechtl's work. He points out that adverse obstetric factors rarely occur singly and has assessed the influence of clusters of adverse factors, using a " risk score" in his analyses.

Prechtl's work also has several implications in research. In particular, he has shown the importance of carefully standardized quantitative methods in developmental neurological examinations and their use as a research tool. It is reassuring that in Britain these methods are already being studied and taught in our more progressive departments of child health.

\section{Miliary Crohn's Disease}

The diagnosis of Crohn's disease can on occasion be puzzling. Recently K. W. Heaton, C. F. McCarthy, R. E. Horton, J. S. Cornes, and A. E. Read ${ }^{1}$ have drawn attention to a form of it which may give rise to difficulties. They describe three patients in whom at laparotomy the conspicuous finding was the presence of many tiny pale nodules on the serosal surface of the bowel. Tuberculosis was initially diagnosed in two of the patients and they were started on antituberculous therapy.

The distinction between Crohn's disease and abdominal tuberculosis is a matter of some practical importance, for corticosteroids might prove disastrous in tuberculosis inadvertently diagnosed as Crohn's disease. The great majority of the granulomatous lesions in the ileo-caecal region are due to Crohn's disease, ${ }^{2}$ and it seems likely that many patients suffering from it were diagnosed in the past as having hyperplastic tuberculosis. Nevertheless, some modern physicians have described the occurrence of tuberculosis of the ileo-caecal region, ${ }^{34}$ so that the possibility of this disease being present cannot be excluded without full investigation.

Histologically, the serosal nodules of Crohn's disease consist of non-caseating granulomata with giant cells of Langhans's type present. Caseation is exceptional in Crohn's disease, whereas it is one of the characteristic features of tuberculous nodules. The granulomata of Crohn's disease are bacteriologically sterile, while those of tuberculosis usually yield tubercle bacilli on culture or guinea-pig inoculation.

One of the patients described by Heaton and his colleagues is of particular interest because the serosal nodules were numerous, though the intestinal wall was barely affected. The authors were then led to postulate that the granulomata are the dominant lesions in early subacute Crohn's disease, and the fact that they follow the lines of lymphatics supports the view that the first pathological changes occur in the

\footnotetext{
' Heaton, K. W., McCarthy, C. F., Horton, R. E., Cornes, J. S., and Read, A. E., Gut, 1967, 8, 4

Lee, F. D., and Roy, A. D., ibid., 1964, 5, 517.

- Howell, J. S., and Knapton, P. J., ibid., 1964, 5, 524.

- Anscombe, A. R., Keddie, N C., and Schofield, P. F., ibid., 1967, 8 , 337.
} 